\title{
Financial Management of the Construction Projects: A Proposed Cash Flow Analysis Model at Project Portfolio Level
}

DOI 10.5592/otmcj.2015.1.6 Research paper

\section{Keywords}

Financial Management, Construction Projects, Portfolio, Cash Flow

\author{
Augustin Purnus \\ Technical University of Civil \\ Engineering, Bucharest, \\ Construction Management \\ Department
}

\author{
Constanta-Nicoleta Bodea \\ Bucharest University of Economic \\ Studies, Centre for Industrial and \\ Services Economics, Romanian Academy
}

bodea@pm.org.ro

CONSTRUCTION SECTOR IS VULNERABLE TO ECONOMIC CHANGES, ESPECIALLY DURING RECESSION PERIODS DUE TO THE HIGH CAPITAL OUTLAYS, COST FLEXIBILITY AND HIGH COMPETITION LIMITING THE PRICE. The changes of the business environment, often associated with shortage of funds, exchange rate fluctuation and political instability are increasing the construction projects financial risks. The actual economical context in the Central and East European countries is characterized by an aggressive competition and a lack of investments in construction area. The common behaviour of the contractor construction companies during these days is to accept a large number of risks beyond their power to mitigate them only to still stay on the business. In order to win the tender, they are bidding lower prices which make them vulnerable to the unexpected events during the project, especially from financial aspects. But the lack of cash during the project progress both at the employer level but mostly at the contractor level leads to delays, penalties and loss of opportunities which are reflected in the health of projects and organizations.

The paper proposes a practical cash flow analysis model, which can be applied by the construction companies mainly when decisions about portfolio structure are taken. Applying this proposed model, the construction companies could avoid high financial exposures and loses. 


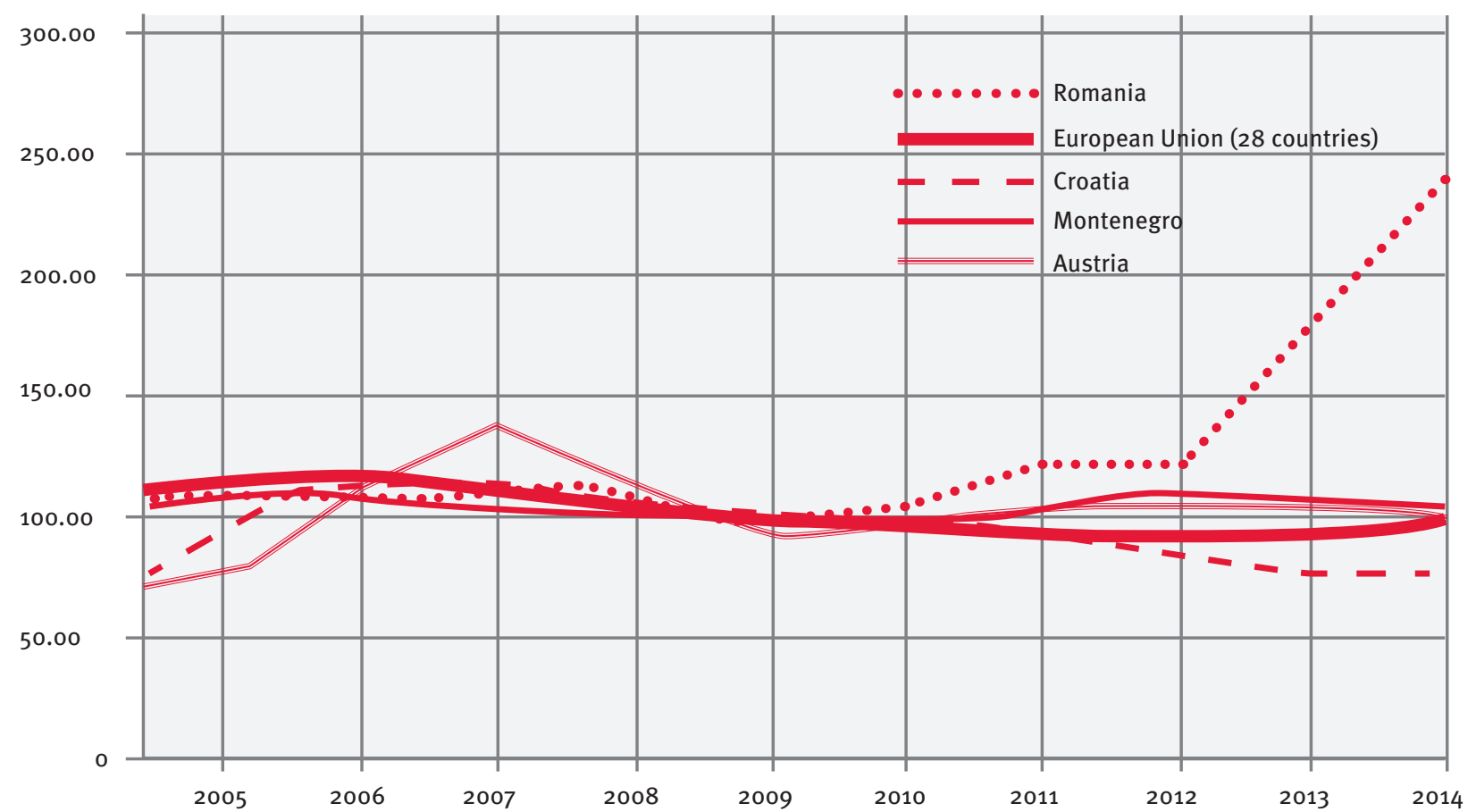

Figure 1. Evolution of the production in construction sector - annual data $(\mathbf{2 0 1 0}=\mathbf{1 0 0})$

\section{INTRODUCTION}

Construction sector is vulnerable to economic changes, especially during recession periods due to the high capital outlays, cost flexibility and high competition limiting the price. The changes of the business environment, often associated with shortage of funds, exchange rate fluctuation and political instability are increasing the construction projects financial risks. Borghezi and Gaudenzi (2013) consider the interest rate of credit, currency and liquidity the factors which generate highest financial risks in construction projects. In (Hlaing et al., 2008) there are listed the most relevant risk factors in the construction industry and the top four risk factors are financial ones: the lack of financial resources of the contractor, the financial stability of the client, the costs overruns and the financial stability.

The common behaviour of the contractor construction companies during the actual economical context in Central and East European countries is to accept a large number of risks beyond their power to mitigate them only to still stay on the business. In order to win the tender, they are bidding lower prices which make them vulnerable to the unexpected events during the project, especially from financial aspects. But the lack of cash during the project progress both at the employer level but mostly at the contractor level leads to delays, penalties and loss of opportunities which are reflected in the health of projects and organizations.

The construction companies are using a limited number of project financial management methods and even fewer methods at project portfolio level (Purnus and Bodea, 2013; Marttonen, 2014; Purnus and Bodea, 2014a). The cash flow analysis is a common method in the construction business, applied mainly at project level. Zayed and Liu (2014) identified the main factors affecting the cash flow and the cash flow forecasting of a single project.
In order to manage financial project risks, most of the companies are focusing on the individual project level that does not reflect the overall risks at a corporate level. The simple sum of individual project's risks can be significantly different from the total risks of enterprise-wide perspectives (Purnuş and Bodea, 2014b). This is why, some techniques from portfolio theory have been proposed, in order to reduce turbulent risk exposures and maximize the total value of the company (Han et all, 2004).

The paper proposes a practical cash flow analysis model, which can be applied by the construction companies at project portfolio level mainly when decisions about portfolio structure are taken. Applying this proposed model, the construction companies could avoid high financial exposures and loses.

The paper starts by presenting the main trends in the evolution of construction sector in the Central and East 


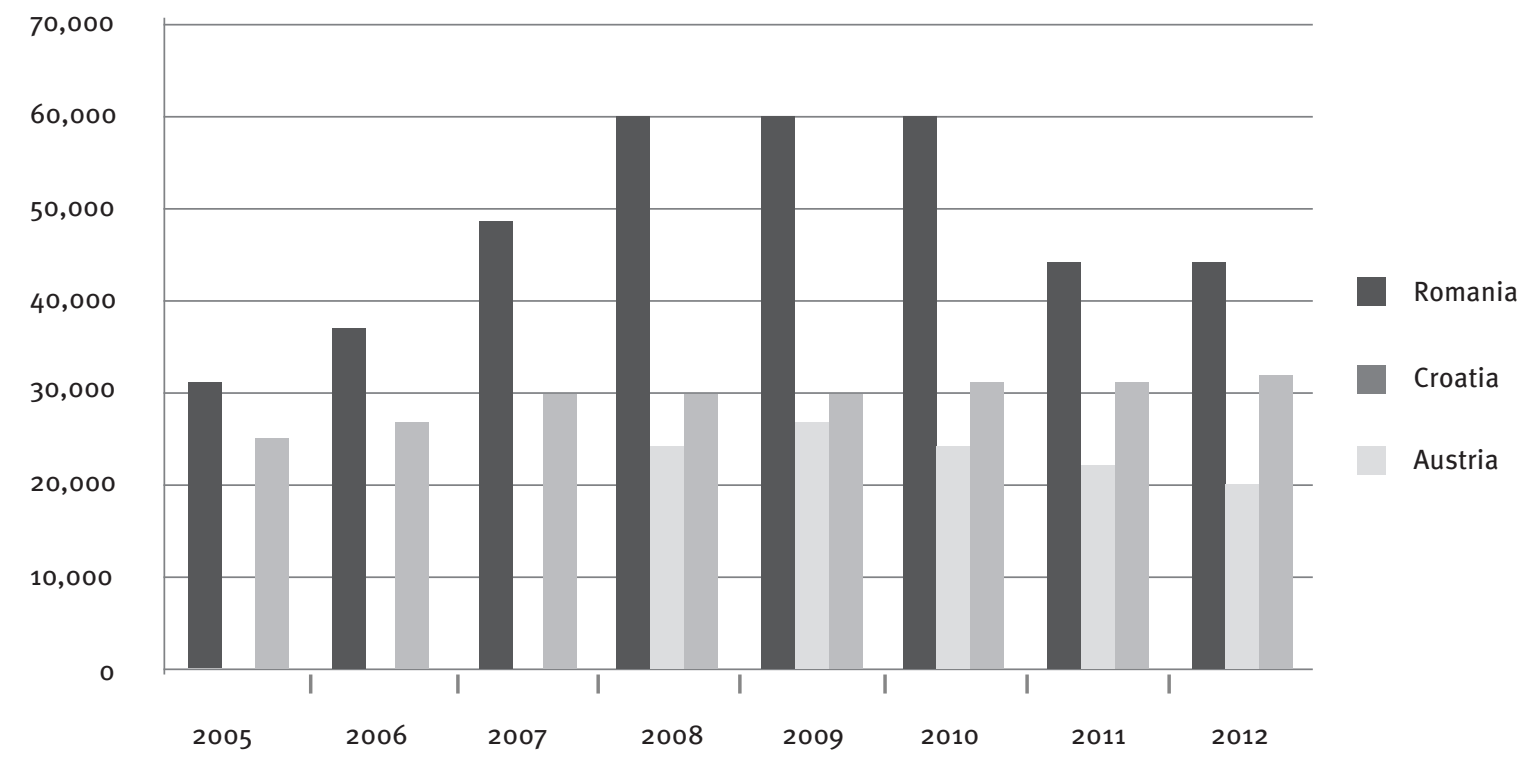

Figure 2. presents the number of construction enterprises in several Central and East Europe countries. We observe that Romania has a higher number of construction enterprises than Austria and Croatia.

Europe. Some detailed information is provided about the Romanian financial challenges in the construction of roads and motorways. Then relevant financial project management practices in the construction sector are discussed, based on the findings of the KMPG survey published in 2015. The proposed cash flow analysis model at the portfolio level is presented as a case study. Finally, during the conclusion part the paper presents and discusses the relevance of the proposed cash flow analysis model.

\section{Evolution of the Construction Sector in Central and East Europe}

According to (Eurostat, 2014), the downturn in activity for construction within the EU-28 lasted longer than for industry. Despite a period of relatively unchanged levels of activity during most of 2010 and 2011, the EU-28 index of production for construction fell during most of 2012 and up until March 2013. During the remainder of 2013 and the first eight months of 2014 there followed a period where construction activity in the EU-28 fluctuate but followed a generally upward path.

After a peak in February 2008, the construction output in the EU-28 fallen, by reaching a low level in February 2010. Between February 2008 and February 2010 the index of

Labour input in construction (number of persons employed) - annual data $(2010=100)$
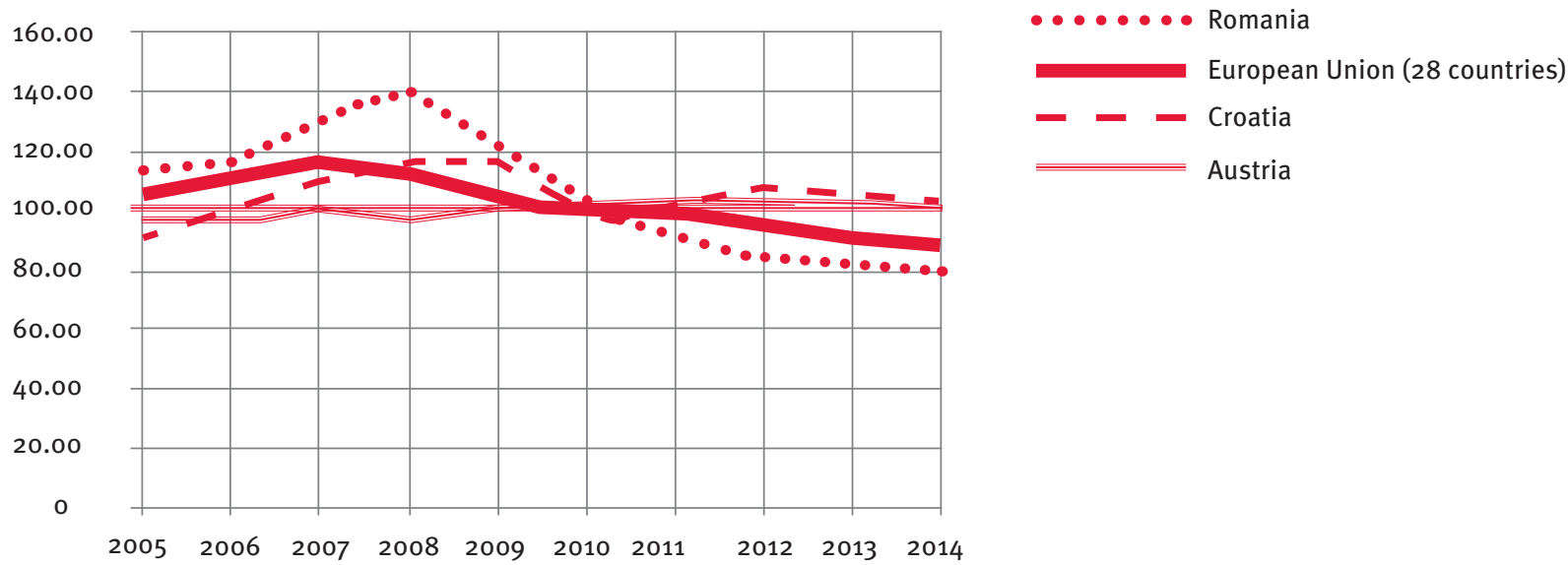

Figure 3. Evolution of the number of person employed in construction sector - annual data $(2010=100)$ 

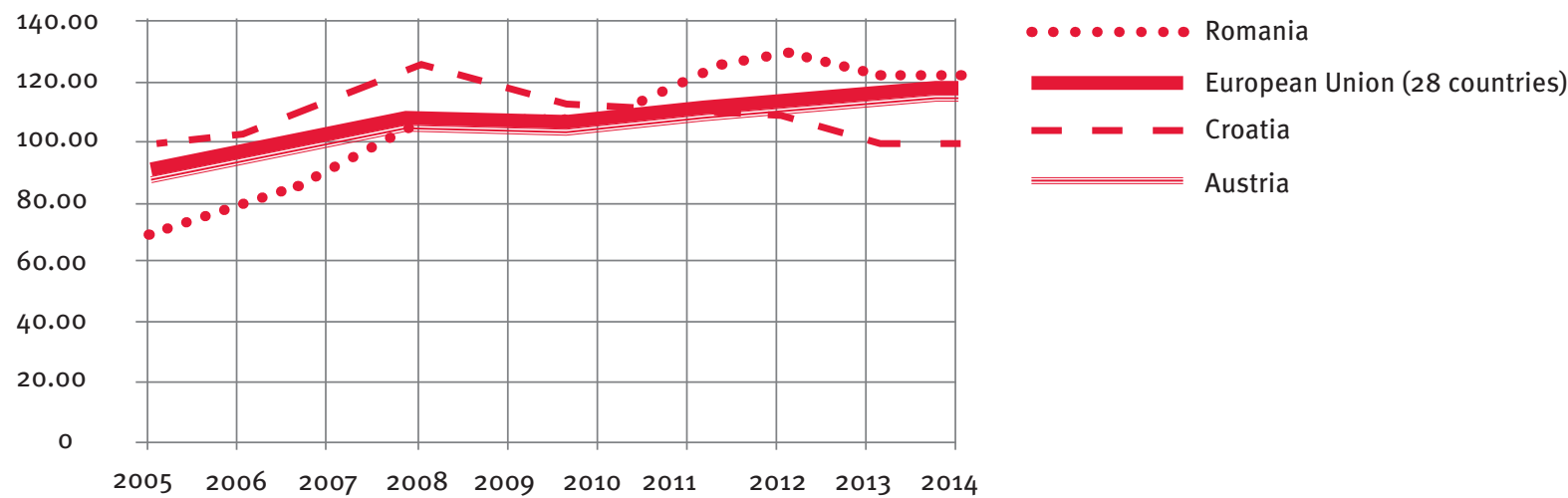

Figure 4. Evolution of the construction cost - annual data $(2010=100)$

production for construction in the EU-28 fell by $18.6 \%$ overall. At the beginning of 2010, construction output remained relatively stable through to September 2011. Thereafter, there was a second downturn in activity within the EU-28's construction sector, with a relative low being reached in March 2013, when output had fallen by a further $9.6 \%$ compared with its September 2011 level. From the spring of 2013 through to August 2014 there was a fluctuating pattern to the development of construction output in the EU-28, although the overall result was an increase of $6.1 \%$ in the level of the index of production.

In figure 1, the evolution of the production in the construction sector is shown, for EU-28 and several Central and East Europe countries. We can see that in 2008, in Romania and Croatia the construction production had in higher level than European Union average. The production recovery after 2010 is closer to the EU-28 trend for Romania than Croatia. We can observe that the evolution of the same indicator in Austria is closer to the EU-28 trend in the period 2008-2010, but the situation after 2010 is more stable than the European average. An interesting pattern is shown by Montenegro. Even if in 2008 the level of the production was lower than EU-28 average, the recovery after 2010 of the construction sector is impressive.

\section{Financial challenges for the} Romanian Construction of Roads and Motorways Sector In 2015, Coface Romania made a sectorial analysis of the construction of roads and motorways for Romania, based on the 2013 financial statements. The analysis conclusions were published in 2015 (Guda, 2015).

According to this study, there was a number of 1.640 Romanian entreprises in 2011, 1.801 in 2012 and 1.829 in 2013. Even if the number of the enterprises is relative stable, the total turnover is downing in 2013 with $22 \%$ comparing with 2012. By analyzing the distribution of these companies according to turnover, Coface identified that about $26 \%$ of companies have not actually carried out any business in $2013.62 \%$ of active companies recorded a turnover of less than EUR $100 \mathrm{~K} /$ year (2013) but the share of value in the total turnover of this segment is only $1 \%$. Only 282 companies in this sector records an annual turnover of more than 1 million euros, representing $15 \%$ of total active companies, but generates about $94 \%$ of the revenues recorded in the entire sector. From the perspective of evolution net earnings in the period 2013 - 2012, $48 \%$ of companies operating in this sector reported a deterioration in net income during 2013 compared to the previous year, almost $30 \%$ of them passing the profit loss. Despite this, the consolidated net result at sector registered a growth upward. $34 \%$ of companies recorded a net loss at the end of 2013 , with $23 \%$ of companies recorded a loss greater than $20 \%$ and $19 \%$ of companies recorded a profit over $20 \%$. Consequently, the net result recorded at sectoral level 2013 was $6 \%$ vs $0 \%$ on the previous year.

Considering how the companies are attracting the funding resources and resource allocation for long-term investments during 2013, the companies recorded a strong decline of the investment policy amid declining sales and poor recovery prospects construction projects. The CAPEX 3 share in total assets was - $33 \%$ for 2013 compared to last year, when CAPEX share in total assets was $7 \%$. Sector companies reviewed were marked by a relatively small working capital in 2013, given that long-term attracted resources covered only marginal long-term investments (tangible fixed assets). The indebtedness recorded at sector registered a growth level recorded in 2013 is $60 \%$. Funding resources are directed mainly short term, given that $59 \%$ of companies are $100 \%$ focused on short-term debt. In this context, the share of short-term debt in total debt rose from $58 \%$ (the level recorded in 2012) to $83 \%$ (2013) analyzed sector 
firms recorded an average extension of payment deadlines, due to the deterioration of the working capital and cash conversion cycle.

Current liquidity recorded in the entire sector during 2013 was 1.23, down from the previous year, when the current ratio was 1.58. Moreover, the coverage of short-term liabilities Net cash decreased by $17 \%$, the level recorded in 2012 to $13 \%$ at the end of 2013. This growth was recorded amid increasing short-term debt and reducing the terms of collection of receivables from 239 days (2012) to 225 days (2013). The decrease liquidity indicators register on the increase balances from suppliers and banks, the average pay short-term debts recorded in 2013 was 269 days, up from the level recorded the previous year, ie 189 days. Given that the average duration of the cycle operational in 2013 was about 292 days, net operating cycle was 23 days, with damage in two months the previous year. Following the stress test analysis, Coface has identified that companies in the sector of construction of roads and motorways register fragile liquidity situation very exposed to negative shocks that may come from non-collection of receivables or falling sales. Coface study confirm the high risk of insolvency of firms in the sector, only $16 \%$ of companies recorded a low risk. Coface individually analyzed during 2014, a total of 335 companies in the sector, which generates $88 \%$ of consolidated turnover at the sectoral level, one of the most important conclusions is that less than one third of the analyzed companies make the payments according to the terms established contractual.

\section{Financial Project Management Practices in the Construction Sector}

In 2014, KPMG (KPMG International, 2014) interviewed from more than 100 private and public organizations around the world, that carry out significant capital construction activity, $38 \%$ of them being European-based. More than a quarter of the respondents worked for government agencies.

The analysis followed four dimensions of the project management practices: preparation (the project planning and prioritizing and the talent management), project risk, controls and governance (project control and project management information systems), project performance (dealing with project failures and contingency planning) and leading relationships (collaboration between the owner and contractor). As some of the main findings regarding the project financial management, we can mention: $84 \%$ of the companies utilize financial and risk analysis to screen projects; $80 \%$ say the majority of capital projects are planned; only $31 \%$ of all respondents' projects came within $10 \%$ of budget in the past 3 years; $58 \%$ are lump sum (fixed price) contracts.

Considering the project delivery strategies, $72 \%$ hold full competitive tenders when awarding contracts. Despite some concerns about a lack of flexibility, the traditional design-bidbuild approach remains one of the two most popular project delivery strategies, enabling the owner to work with various suppliers for different aspects of the project.

According to Jeff Shaw (KPMG International, 2014) “organizations need to manage their capital efficiently and effectively across a wide range of projects, to ensure they are aligned with strategic goal. ...Throughout the capital allocation process, alignment between strategic objectives and the capital project portfolio must be tested". The organizations should have in place capital budgeting and planning policies and procedures, a crossfunctional capital review committee, and a robust system for tracking and reporting across the portfolio.

One of the biggest concerns expressed by the survey participants is the accuracy of the estimated costs before committing to the project. It would be difficulties where the applied contingency model (for example, 10 percent model) is not useful to cover the project risks. "Contingency planning typically involves downside risk estimates for budget and delivery times throughout the project life cycle. According to the participants, a range of methods is used to calculate contingency levels. The survey findings indicate that bigger organizations (which tend to have larger and more complex projects) are more likely to take a conservative view of contingency levels. Over half of the respondents from this segment report that the typical range of contingency is greater than 10 percent of the total estimated cost. Arguably, the size and scale of their project portfolios have led to a cautious attitude, tempered by past project cost overruns" (KPMG International, 2014). The type of contract which is the base of the relationship between the parties have significant effects on the strategy the construction company will take in order to achieve it purposes in terms of cost, duration and profit.

The main project financial management processes includes: project financial planning (identification of financial needs, understanding the contract requirements, estimating financing costs, establishing the financing points, sensitivity analysis, developing and testing the financial project plan, assigning responsibilities), project financial control (monitoring key influences and taking corrective measures when necessary) and administration and records (designing and maintaining a financial information database).

Most of the companies develop financial projections methods based on the deterministic estimation of project financial performance. For doing that, some basic assumptions are considered, such as: the time frame (the financial projections cover the project implementation period plus three-five 
years after the project's completion), capital outlays and financing costs (they include any up-front and ongoing capital needs during the reference period), revenues associated with the project, expenses, and capital structure. In a probabilistic approach, the financial indicators are considered as being uncertain variables, with discrete probability distributions. Working with stochastic variables leads to the increasing of computational effort. A financial model connecting the project analysis with the portfolio and/or organizational level could avoid high financial exposures and loses for the construction companies. The following section presents a two-level model for financial analysis. This model is introduced by a case study.

\section{Cash flow analysis model: a case study}

The proposed cash flow analysis model includes two interrelated levels: the project level and the project portfolio level.

At the project level, each project is analyzed from aspects related to scope, time, resources, cost, contract conditions of payments during the projects execution and those related to risk identification and prioritization and risk response plan.

At the project portfolio level, the aggregation of projects into portfolio is performed. The need of resources for projects completion is estimated and the portfolio cash-flow is developed. The final step is to develop financing and return of financing scenarios in

The projects and portfolio contract price are presented in the table 1.

\begin{tabular}{|c|c|c|}
\hline Name & Duration & Contract Price (Euro) \\
\hline Portfolio & 36 months & $47,238,320$ \\
\hline Project 1 & 21 months & $15,518,964$ \\
\hline Project 2 & 14 months & $7,027,800$ \\
\hline Project 3 & 24 months & $5,527,942$ \\
\hline Project 4 & 14 months & $11,687,742$ \\
\hline Project 5 & 11 months & $7,475,872$ \\
\hline
\end{tabular}

Table 1: projects and portfolio contract price

order to get a project portfolio cash-flow always positive, thereby providing complete support in performing all the projects within the project portfolio. This is intended to establish both the time and the amount of funding for covering the projects implementation in each time period and respectively the time and the amount of return of funding. The result is represented by the combined cash-flow of cost, incomes, financing and return of financing which must be always positive.

The case study analyzes the cash flow of a middle size construction company which awarded during 2013 and 2014 five contracts of infrastructure construction projects. The projects are $85 \%$ EU founded and $15 \%$ co-finance by the Contracting Authorities, and the contracts are based on FIDIC 1999 Conditions of Contract. The project portfolio is consisted of five projects with a total duration of three years (figure 5). The first three projects are for the construction of waste water plants, the forth is related to the rehabilitation of a water supply and waste water network and the fifth project is the rehabilitation of a road. The projects for the construction of the waste water plants use the FIDIC 1999 Conditions of Contract for Plant and Design-Build for Electrical and Mechanical Plant and for Buildings and Engineering Works Designed by the Contractor (Yellow Book), while the last two projects use the FIDIC 1999 Conditions of Contract for Constructions for Buildings and Engineering Works Designed by the Employer (Red Book) amended by the Particular Conditions.

Due to the overlapping of the projects, the distribution of the contract price over the time for the entire portfolio (figure 6) highlights that during October 2014 - August 2015, the works to be performed per month are over 2,000,000 Euro, with a maximum value of $5,626,187$ Euro in July 20

According the FIDIC 1999 clause 14 (Contract Price and Payment) from the General Conditions of Contract, the payment after the end of each month (Red Book) or after the period of payment stated on the contract (Yellow Book) will be made by the Contracting

\begin{tabular}{|c|c|c|c|c|c|c|c|c|c|c|c|c|c|c|c|c|c|c|c|c|c|c|c|c|c|c|c|c|c|c|c|c|c|c|c|c|c|}
\hline \multirow{2}{*}{ Name } & \multicolumn{12}{|c|}{2014} & \multicolumn{10}{|c|}{2015} & \multicolumn{10}{|c|}{2016} & \multicolumn{5}{|c|}{2017} \\
\hline & 1 & $F$ & $M$ & A & $\mathrm{M}$ & I & & $A$ & $S$ & 0 & v & D & 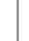 & $\mathrm{F}$ & $M A$ & $M$ & I & 1 & A S & 0 & $\mathrm{~N}$ & D & I & $\mathrm{F} M$ & A & $M$ & 1 & I & $\mathrm{A}$ & $\mathrm{S}$ & & $\mathrm{V} D$ & I & $\mathrm{F}$ & $M$ & & $M$ \\
\hline Protfolio & & & & & & & & & & & & & & & & & & & & & & & & & & & & & & & & & & & & & -0 \\
\hline Project 1 & & & & & & & & & & & & & & & & & & & & & & & & 0 & & & & & & & & & & & & & \\
\hline Project 2 & & & & & & & & & & & & & & & & & & & & & & & & & & & & & & & & & & & & & \\
\hline Project 3 & & & & & & & & & & & & & & & & & & & & & & & & & & & & & & & & & & & & & -0 \\
\hline Project 4 & & & & & & & & & & & & & & & & & & & & & & & & & & -0 & & & & & & & & & & & \\
\hline Project 5 & & & & & & & & & & & & & & & & & & & & & & & & & & & & -0 & & & & & & & & & \\
\hline
\end{tabular}




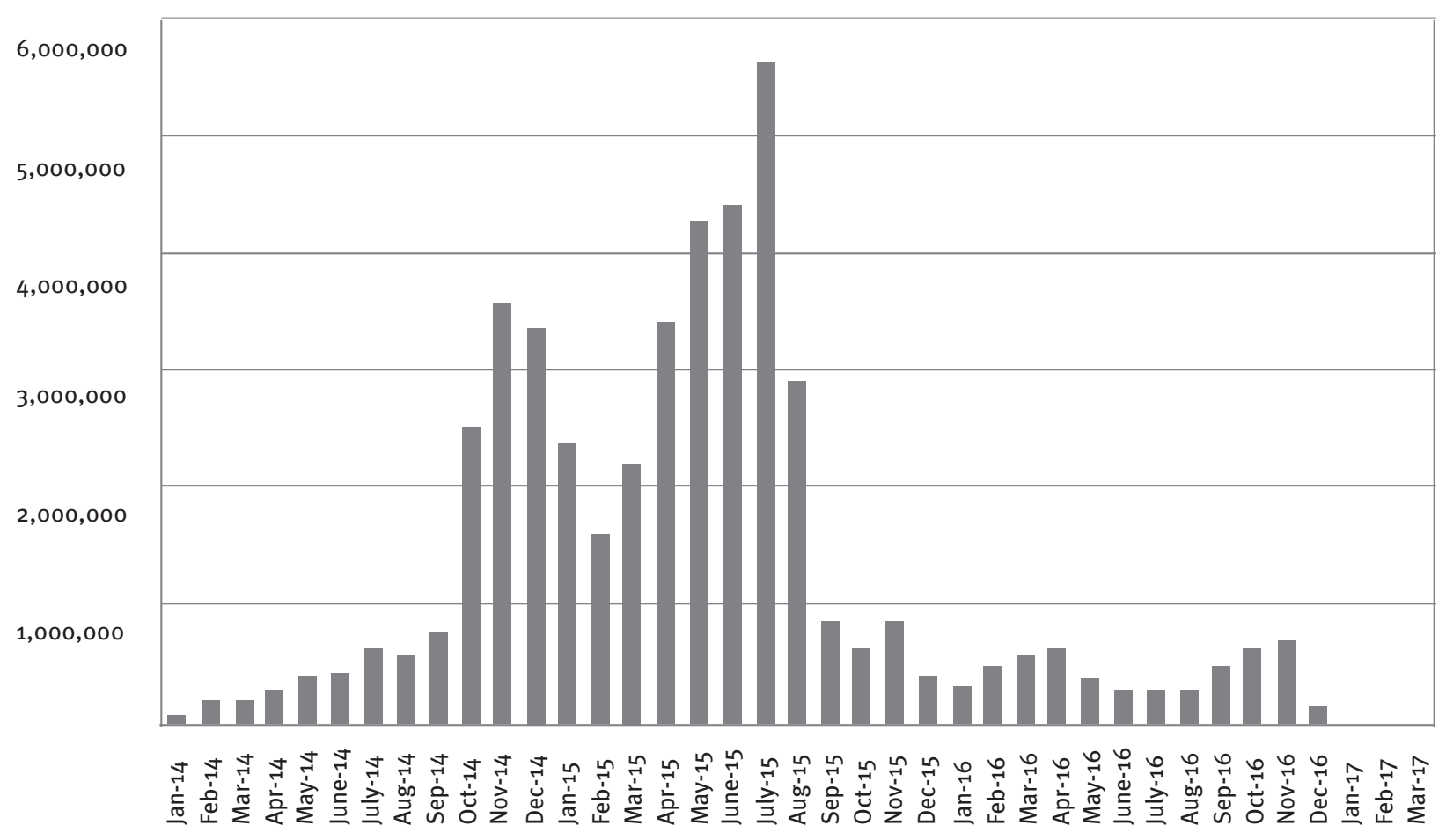

Fig. 6. Portfolio distribution of the contract price over the time

Authority in maximum 56 days (figure 7). If through Particular Conditions of Contract this clause is amended by increasing the time for payment as it often happened, than the financial effort made by the construction company increase, bringing a supplementary risk to its capability to run the projects. Therefore the top management decision to participate in the bid should be based not only on their technical ability but mainly on the company financial capability.

\section{Contractor submit the statement} after the end of the period of payment GCC $14 \cdot 3$

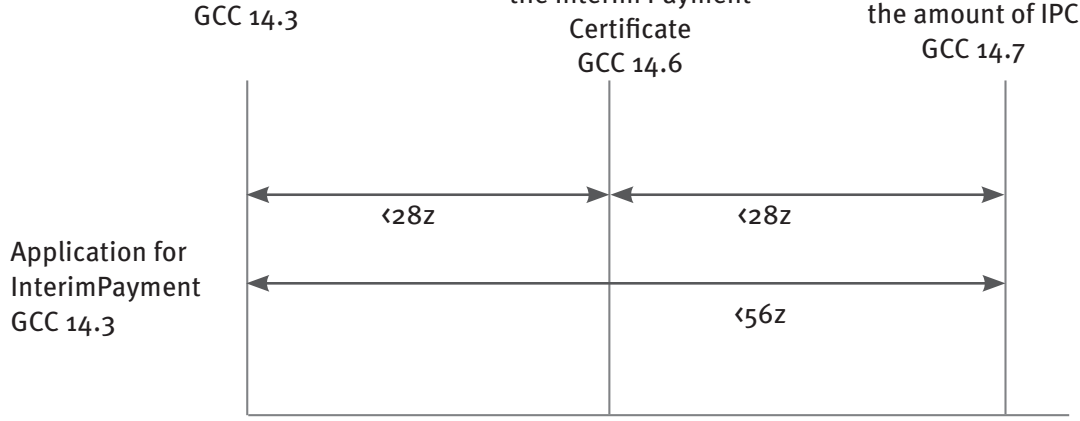

Fig. 7. Time period for payment of statements
The contractor costs involve the costs with manpower, materials, equipment's, transport, other direct costs and overhead. Each project cash flow is composed from the project costs and the incomes from the payments, according the time period stated in the individual contracts. The cash flow for each project is shown in figure 8 .

It should be mention that analyzing the projects cash flow, almost all the project duration the works must be supported from the construction company reserves or from external finance. This behavior has a significant impact on the company liquidity forcing it to access other financial sources like bank loans. The peak of the cash flow and the weight from the contract price is presented in the table 2 .

Two conclusions can be drawn analyzing the above table:

- For projects with relatively short durations and monthly payment, the amount of money the construction company need to have is around $70 \%$ from the contract price, while if the payment is made after finishing significant parts of the project, than the amount of money can increase at $90 \%$ from the contract price.

- For the projects with long duration, no matter the payment is made monthly or after the finish of significant parts, the amount of needed money to sustain the construction works is around $35 \%$ from the contract price.

Focusing on individual cash flow projects without taking into account that 


\begin{tabular}{|c|c|c|c|c|}
\hline Name & Duration & $\begin{array}{c}\text { Contract Price } \\
\text { (Euro) }\end{array}$ & $\begin{array}{c}\text { Peak of Cash Flow } \\
\text { (Euro) }\end{array}$ & Weight \\
\hline Project 1 & 21 months & $15,518,964$ & $5,876,472$ & $37.87 \%$ \\
\hline Project 2 & 14 months & $7,027,800$ & $6,401,396$ & $91.09 \%$ \\
\hline Project 3 & 24 months & $5,527,942$ & $2,021,373$ & $36.57 \%$ \\
\hline Project 4 & 14 months & $11,687,742$ & $7,918,731$ & $67.75 \%$ \\
\hline Project 5 & 11 months & $7,475,872$ & $5,505,571$ & $73.64 \%$ \\
\hline
\end{tabular}

Table 2: The peak of the cash flow and the weight from the contract price

in fact they are developed with the company limited resources (manpower, materials, equipment's and money) is a big mistake. As time as the decisions on providing resources is take at the company level, the most important decision tool is the portfolio cash flow.
By aggregating the projects cash flow, we will obtain the portfolio cash flow (figure 9) with a peak of 18,135,956 Euro, representing $38.39 \%$ from all the contracts price and an estimated profit at the end of projects of $2,218,743$, representing $4.7 \%$.
The evolution of the portfolio cash flow shows that in order to complete in time the projects, the company need at least the amount of money represented by the cash flow peak.

For this reason several scenarios of financing and return of financing were performed. The optimum scenario or at least, the close to the optimum scenario which will insure the company will have always money to run the projects in the contractual duration. The results shows not only when, but mostly what amount of money should be borrowed or obtain from internal or external sources and when and what amount of money should be return.
Project 1

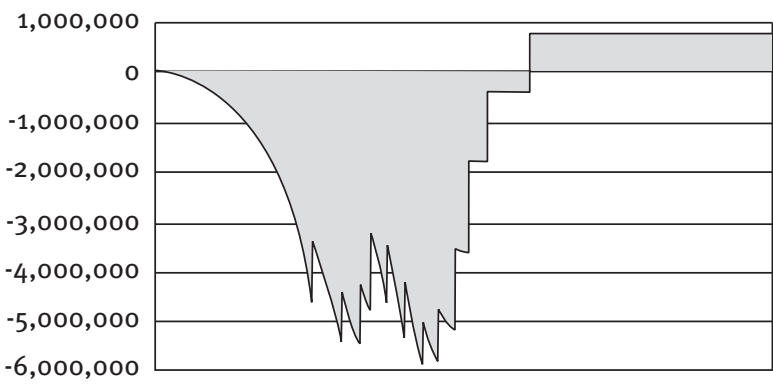

Project 3

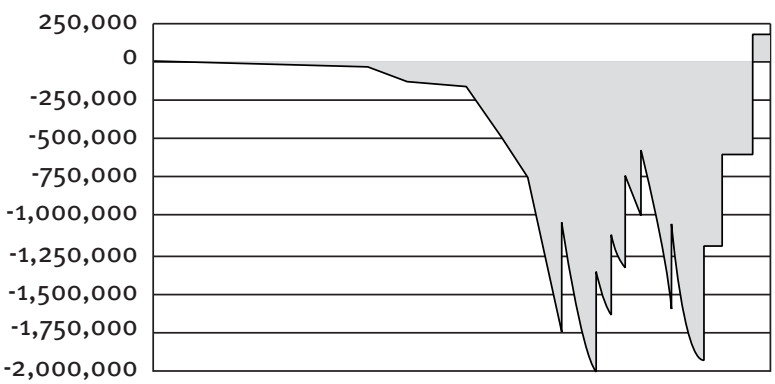

Project2

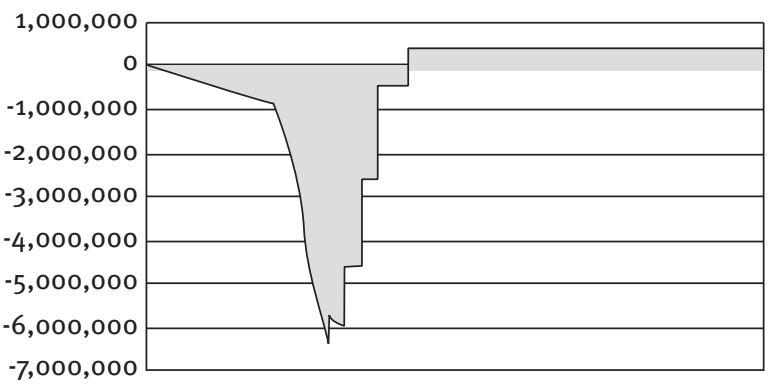

Project 4

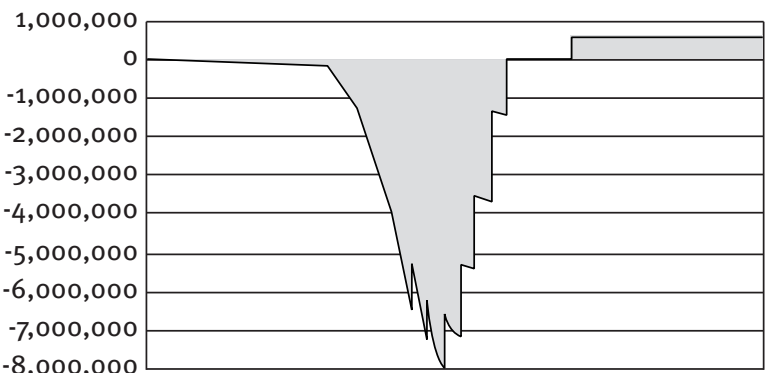

Project 5

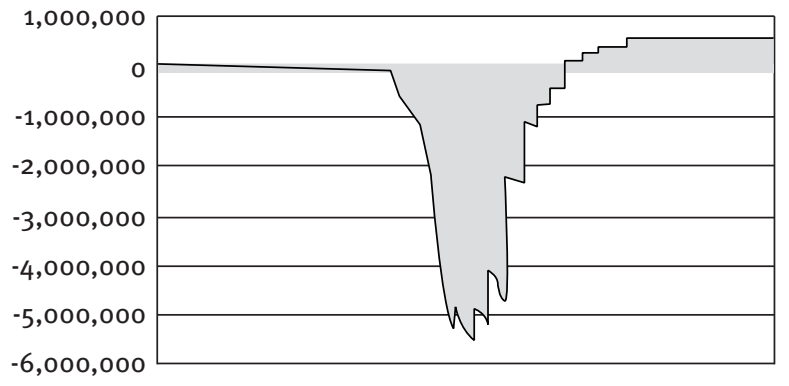

Fig. 8. Projects cash flow 


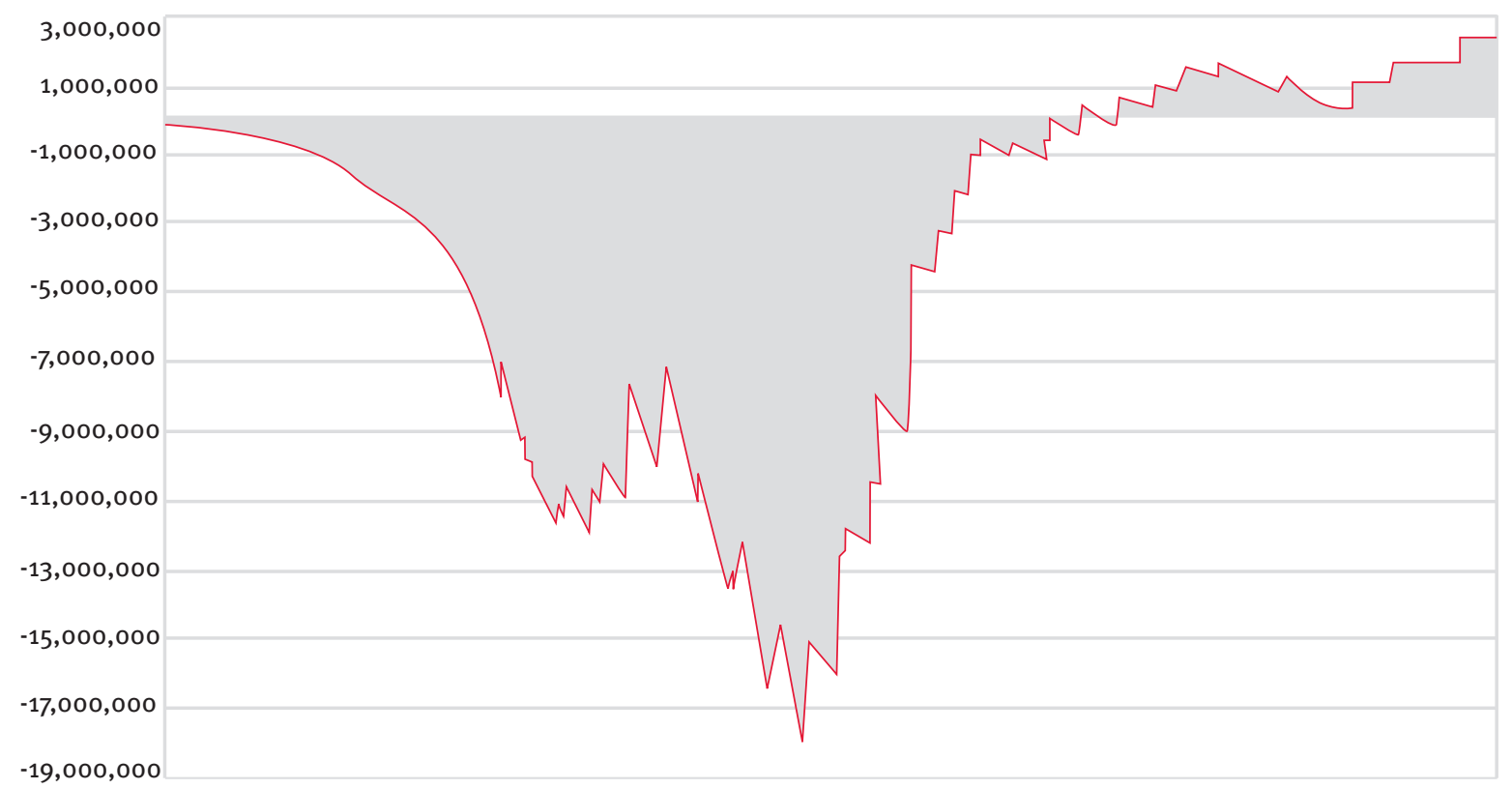

Fig. 9. Portfolio cash flow

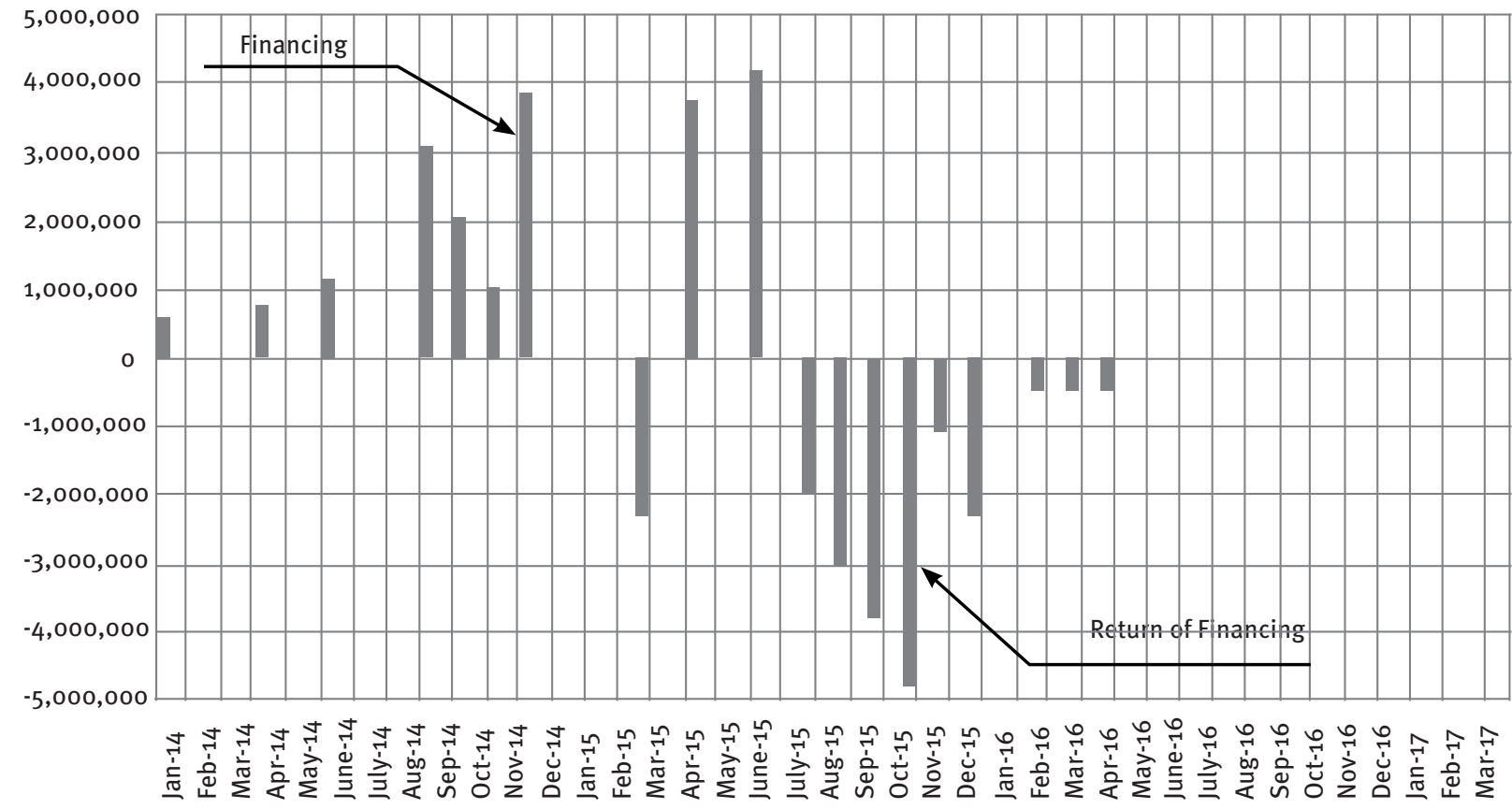

Fig. 10. Monthly financing and return of financing

In figure 10 is presented the monthly schedule offinancing and return of financing. In order to cover the portfolio cash flow peak, a total value of 20,435,956 Euro is needed to be obtain, representing $43.26 \%$ from all the contracts price.
The cumulative curves in the combined view of portfolio cash flow, financing and return of financing are presented in figure 11.

The combination of the portfolio cash flow, the income from the contracts payment, the financing and the return of financing represent the company cash flow and is the real decision tool by the top management (figure 12). It should be always on positive values, otherwise the projects will not be sustained. 


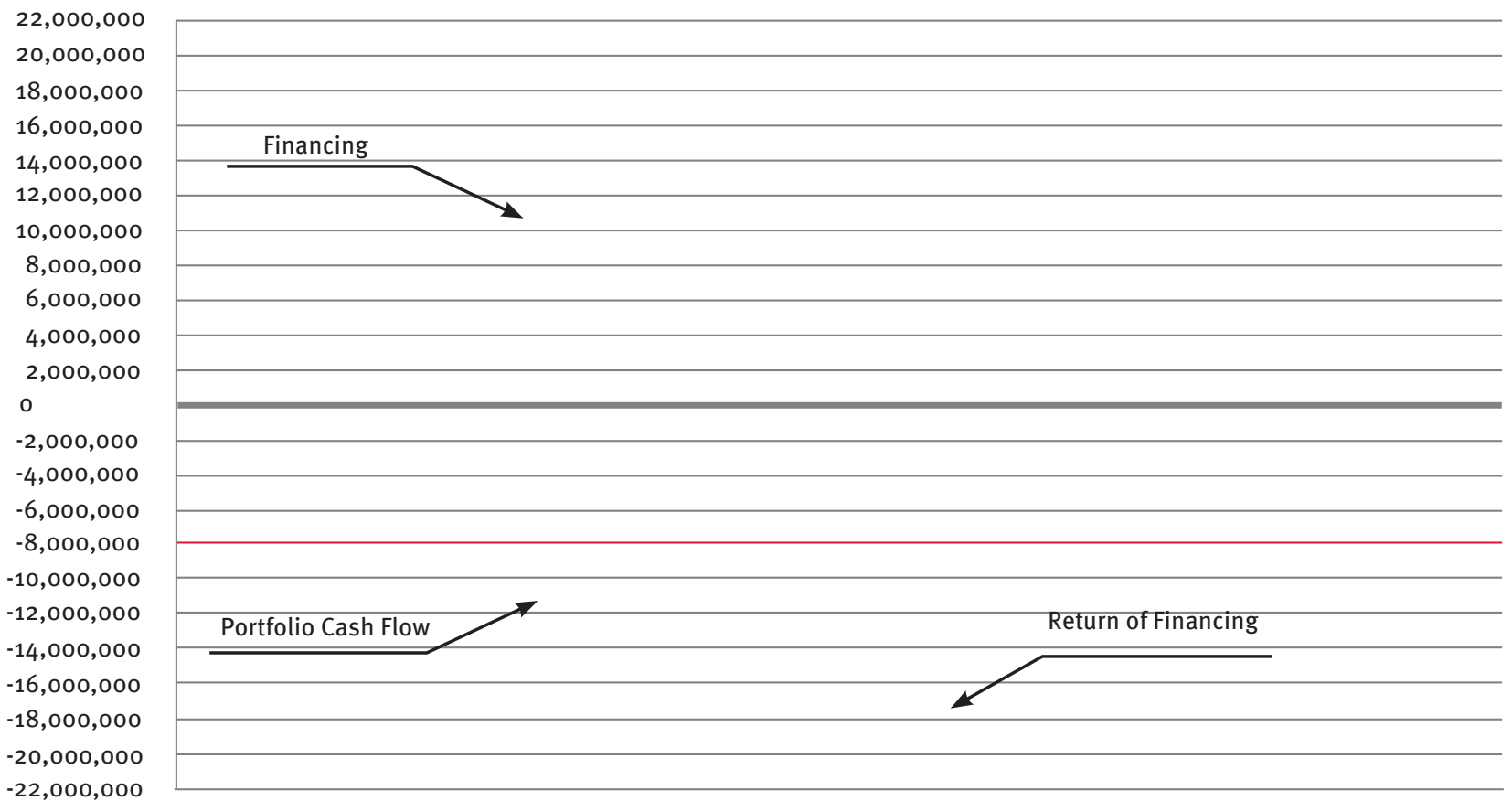

Fig. 11. Combined analysis - portfolio cash flow, financing and return of financing

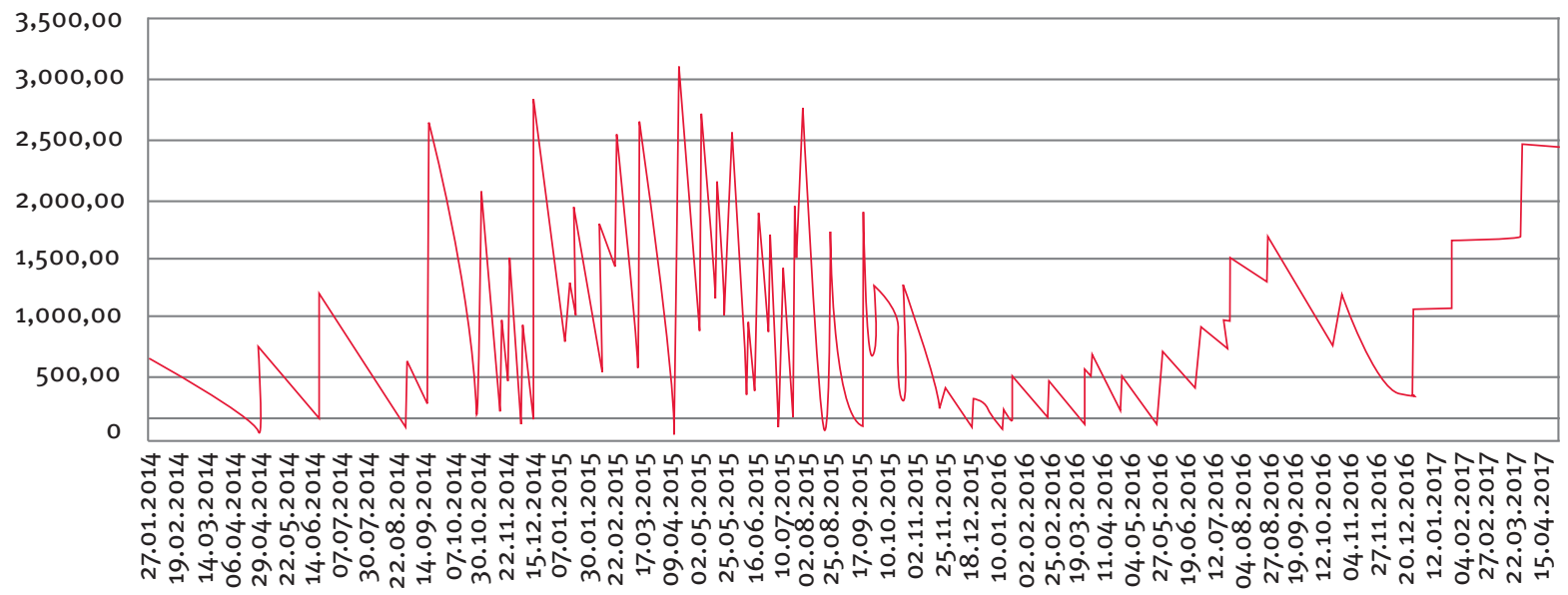

Fig. 12. Combined cash flow -financing, income from payments, costs and return of finance

However, the construction projects are very complex and have a large number of risk events and uncertainties which may occur during their execution. Therefore a deterministic analysis will not be able to provide a realistic view of the financial efforts the construction company has to make, as time as the projects are highly dynamic. A probabilistic analysis will allows to integrate the risk events and uncertainties and to become a true decision tool.

\section{Conclusions}

The paper proposes a practical cash flow analysis model, which can be applied by the construction companies at project portfolio level mainly when decisions about portfolio structure are taken. Applying this proposed model, the construction companies could avoid high financial exposures and loses.

The type of contract which is the base of the relationship between the parties have significant effects on the strategy the construction company will take in order to achieve it purposes in terms of cost, duration and profit. Analyzing the projects cash flow, almost all the project duration the works must be 
supported from the construction company reserves or from external finance. This behavior has a significant impact on the company liquidity forcing it to access other financial sources like bank loans. The evolution of the portfolio cash flow shows that in order to complete in time the projects, the company need at least the amount of money represented by the cash flow peak.

The proposed model allows construction companies to predict not only when, but mostly what amount of money should be borrowed or obtain from internal or external sources and when and what amount of money should be return. A deterministic analysis will not be able to provide a realistic view of the financial efforts the construction company has to make, as time as the projects are highly dynamic, but a probabilistic analysis will allows to integrate the risk events and uncertainties and to become a true decision tool. Due to the high amount of money needed to perform the projects, it become reasonable to say that construction companies need a specialized bank and not commercial one, which will supports their financial needs.

Further improvements will be made to the cash flow analysis model taking into account the risk events and uncertainties, in order to make a feasible tool for decision making.

\section{References}

Borghesi, A. and Gaudenzi, B. (2013), “Risk Management: How to Assess, Transfer and Communicate Critical Risks", Springer, Milan.

Eurostat (2014), “Industry and construction statistics - short-term indicators”, available at: http://ec.europa.eu/eurostat/ statistics-explained/index.php/Industry and_construction_statistics_-_short-term_ indicators, (accessed 10 May 2015).

FIDIC, 1999, Conditions of Contract for Plant and Design-Build for Electrical and Mechanical Plant and for Buildings and Engineering Works Designed by the Contractor

FIDIC, 1999, Conditions of Contract for Constructions for Buildings and Engineering Works Designed by the Employer

Guda, I. (2015), „Analiza sectoriala: Lucrari de constructii ale drumurilor si autostrazilor", Coface Romania, available at: http:// www.coface.ro/Stiri-Publicatii/Publicatii/ Analiza-sectoriala-Lucrari-de-constructii-aledrumurilor-si-autostrazilor (accessed 10 May 2015).

Han, S.H., Diekmann, J.E.; Lee, Y. and Ock J. H. (2004), Multicriteria Financial Portfolio Risk Management for International Projects, Journal of construction engineering and management, May/June

Hlaing, N.N., Singh, D., Tiong, R.L.K. and Ehrlich, M. (2008), "Perceptions of Singapore con-struction contractors on construction risk identification", Journal of Financial Management of Property and Construction, vol. 13 , no. 2, pp. 85-95, Emerald Group Publishing Ltd.
KPMG International (2015), “Climbing the curve, Global Construction Survey 2015”, KPMG International Cooperative available at: http://www.kpmg.com/global/en/ issuesandinsights/articlespublications/ global-construction-survey/pages/globalconstruction-survey-2015.aspx (accessed 10 May 2015)

Marttonen, S. (2014), “Creating risk measurement model to project portfolio management in construction company", Lappeenranta University of Technology, School of Industrial Engineering and Management, Tampere

Purnuş, A., Bodea, C. (2013), “A probabilistic approach of construction project financial management", Creative Construction Conference, Budapest, ISBN 978-963-269366-8, pp.649-66o

Purnuş, A., Bodea, C. (2014a), “Project prioritization and portfolio performance measurement in project oriented organizations", Procedia - Social and Behavioral Sciences, 27th IPMA World Congress, 119(2014), pp. 339-348, Elsevier Ltd, DOI: 10.1016/J.SBSPRO.2014.03.039, ISSN: $1877-0428$.

Purnuş, A., Bodea, C. (2014b), “Correlation between Time and Cost in a Quantitative Risk Analysis of Construction Projects”, Procedia Engineering, Volume 85, Pages 436-445, Elsevier Ltd.

Zayed, T. and Liu Y. (2014), "Cash flow modeling for construction projects”, Engineering Construction and Architectural Management, Vol. 21, No. 2, pp. 170-189, Emerald Group Publishing Ltd. 